International Journal of Solar Thermal Vacuum Engineering

\title{
Factors influencing the performance parameters of vacuum glazed smart windows to net zero energy buildings
}

\author{
Saim Memon ${ }^{1,}{ }^{*}$, Yueping Fang ${ }^{2}$, Essam Mohamed Abo-Zahhad ${ }^{3}$, O Abdelrehim ${ }^{4,5}$, Mohamed R. \\ Elmarghany ${ }^{4,5}$, Abdul Rashid Memon ${ }^{6}$, Shanwen Zhang ${ }^{7}$, Amos Darko $^{8}$
}

\footnotetext{
1 Solar Thermal Vacuum Engineering Research Group, London Centre for Energy Engineering, School of Engineering, London South Bank University, London, United Kingdom

2 Coventry University, School of Energy, Construction and Environment, Coventry, United Kingdom

3 Mechanical Power Engineering Department, Faculty of Energy Engineering, Aswan University, Aswan, Egypt

4 Mechanical Power Engineering Department, Faculty of Engineering, Mansoura University, El Mansoura, Egypt

5 Mansoura University Nanotechnology Center, Mansoura University, Mansoura, Egypt

6 Department of Civil Engineering, Faculty of Engineering Science \& Technology, Ziauddin University, Karachi, Pakistan

7 College of Mechanical Engineering, Yangzhou University, Yangzhou, China

8 Department of Building and Real Estate (BRE), The Hong Kong Polytechnic University, Kowloon, Hong Kong.
}

\section{ABSTRACT}

The progression of smart technologies such as vacuum glazed windows are considered a realistic achievement of the net energy zero buildings (NZEBs). From designers to researchers to builders, there has been an increasing concern about understanding the inter-dependencies between the parameters and influencing factors that determine the performance of vacuum glazed smart windows. This research reviews the performance parameters such as thermal transmittance ( $U$ value), thermal resistance ( $R$ value), solar transmittance ( $g$ value), visible light transmittance ( $\tau \vee v a l u e)$ and thermal resistance of residual gas space ( $R_{\text {gas }}$ value). These are inter-dependent on factors such as edge seal, support pillar array, low emittance coatings, getters, and effective evacuation process. This research implicates that effective hermetic edge seal provides longevity such as fusion and solder glass edge sealed vacuum glazing could be cost-effective and energy efficient solution. Stainless steel support pillar array is an unavoidable compromise on $U$ value. This review shows that an increase of the size of glass sheet increases support pillar array improving the overall $U$ value. Also, an addition of low emittance coatings enhances $U$ value whilst maintaining $\tau v$ value. To improve the overall life span of the vacuum glazed smart window, an incorporation of combo-getter that absorb any gases released from the internal glass surfaces in to into the vacuum cavity from the glass surface which prevents degradation of vacuum pressure and provide long term vacuum pressure stability in the vacuum glazed smart window. A recent improvement in the understanding of evacuation process shows that hot-plate surface heat induction of $60^{\circ} \mathrm{C}$ improved the vacuum pressure and mitigates the pump-out hole sealing process whilst lessening the temperature induced stresses.

\section{Keywords:}

Vacuum Glazing; Thermal Transmittance;

Edge Seal; Getters; Evacuation Process

Copyright $@ 2020$ PENERBIT AKADEMIA BARU - All rights reserved

\section{Introduction}

Noteworthy research efforts are devoted to the net zero energy buildings (NZEBs) which can be achieved through smart technologies including vacuum glazed windows [1]. The efforts of the global countries are dedicated to the mission of reducing their net $\mathrm{CO}_{2}$ emissions towards zero and such

\footnotetext{
* Corresponding author.

E-mail address: S.Memon@lsbu.ac.uk
}

https://doi.org/10.37934/stve.2.1.118 
that building sector plays a significant role in achieving this mission [2]. A key issue in the construction of NZEBs is to improve their heat transfer characteristics by means of high-performing insulation of the building façade [3]. In which, vacuum glazed smart windows allow larger window-to-wall area ratios [4] with lower heat loss characteristics. There has been an increasing concern of understanding the complexity and performance parameters that vacuum glazed smart window features. Therefore, this work discusses the performance parameters and factors that affect vacuum glazed windows.

\section{Connotation of Smart Windows}

A typical industrial standard glass is often referred as "float glass". The procedure for developing float glass was first established by Alastair Pilkington in 1952 [5]. Pilkington had proposed a standard synthesis route for manufacturing high quality glass. Initially, the procedure only enabled glass with a thickness of $6.8 \mathrm{~mm}$ to be obtained. However, through clever and controlled adjustments glass thicknesses today can be achieved between the range of $0.4 \mathrm{~mm}$ to $25 \mathrm{~mm}$ whilst still maintaining the main principles of Pilkington's method [6]. The development of float glass came at a crucial time as it enabled an architectural revolution to take place as skyscrapers started to become a common theme with cities buildings. They became more daring since stronger, larger, and more durable glazed windows could be produced. To understand the future of smart window technologies, it is important to reflect on how far the industry has come and the key inventions that brought the industry forward. The primary purpose of smart windows, which are characterised as an opening in wall or roof of a building or vehicle fitted with glass in a frame, is to admit light and air and to allow people to see with minimum compromise of heating bills caused by the heat loss through it [7]. From this definition, problems, and potentials of current windows can be investigated and blueprints for an ideal smart window can be derived. Today, windows are more than merely a structure within a building used to gain access to vision of outside environment. Also, windows have an extremely important role within architectural design and limitations to NZEBs. They also continue to play an increasingly significant role in the insulation and visibility performances achieved by NZEBs. On one hand, as society begins to become more conscious of the depleting supply of fossil fuels the demand for energy conservation and renewable technologies continues to grow [8]. On the other hand, the waste heat energy via thermoelectric $[9,10]$ with the use of concentrated solar power technologies [11,12] and its integration to electric vehicles having the potential influence on charging of batteries and interconnection to charging stations in terms of power quality are ongoing challenges $[13,14]$. The increasing importance of efficiency with performance continues to be an aspect, which strives engineers and designers to redevelop modern equipment. This is where the current design of vacuum glazed smart windows begins to be prospered [15]. Cities and other areas of high infrastructure continue to play an important contribution in global energy consumption. A significant proportion of the energy supplied to high-rises is used just to regulate the internal building temperature through systems such as central heating and air conditioning system [16]. All business financiers understand the fundamental and crucial role that utility bills play in the operating costs associated with a corporation. The thermal and illumination characteristics associated with modern windows have been often found to have links to the bio-psychological and skin health of the occupants as well as acoustic and light comfort [17]. The working conditions and environmental comfort in which employees are exposed at work are becoming increasingly important to the corporations, especially for those which are office-based as links have been identified between employee comfort and productivity. The present display of windows presents potential opportunity for market to design smarter windows. Investing into smart windows technology seems to be favourable option for many residential and commercial homes solely down to their enhanced optical properties which promises 
to significantly reduce heat loss and improve radiance achieve in rooms that helps corporations to save money whilst also improving employee productivity.

To understand why windows are responsible for heat loss, a good understanding of the main principles of heat transfer is required [18]. Heat transfer to and from windows occurs via three processes: conduction, convection, and radiation. All three modes of heat transfer play a part in the distribution of heat within a building and designers need to consider all aspects if sustainable windows are to be developed to minimise heat loss through it. Conduction describes the process at which heat is transferred through the glass sheets, spacers, edges, and frame. This heat transfer occurs at a molecular level when heat is applied to a solid object the heat or thermal energy is transferred onto particles enabling the particles to gain more energy and vibrate more and release heat. In windows, convection occurs across the airgap, compared with metals, glass is considered to be poor heat conductor. The difference in response to heat occurs due to the difference in molecular arrangement of both methods. Metals are widely known to be good conductors of heat due to the close arrangement of metal ions in the lattice which enables the delocalised electrons to carry kinetic energy through the lattice. Whilst glass is known to be poor insulator of heat due to similar but opposite reason in glass the electrons are held more tightly than metals enabling glass to resist the heat transfer since electrons move as freely and transfer energy. This implies that for smart windows, heat transfer by conduction and convection should be reduced. However, there are other elements where heat loss through convection does occur which is due to intermittent opening of the smart windows. Heat transfer by radiation occurs when sunlight penetrates through smart windows, solar radiation interacts with the glass some of the radiation is reflected, some is transmitted whilst the remained is absorbed by the glass heating it, resulting in formation temperature difference between window and the environment a temperature gradient is established and the window is now able to reradiate the heat [19]. Sunlight consists of a mixture of radiation within the electromagnetic spectrum consists of two main specific wavelengths: short-wavelength radiation, which is composed of mainly infrared radiation, and long-wave which is composed of mainly Ultraviolet radiation. Smart window technologies discussed in [20] aim to limit the effect that radiation has on windows by enhancing and controlling the proportion of radiation which is reflected, transmitted, and absorbed.

The market size of smart windows predicts the industry to reach a market value of $\$ 700$ million dollars by 2024. In 2020, the re-shaping and re-engineering of office buildings due to COVID-19 Pandemic [21] has steeply increased the market value of smart windows that plays a key role in achieving socially distanced offices. Growth in research and development of window technologies continues to grow year after year with the development of "smart homes" with the purpose of creating sustainable living [22].

\section{Performance parameters for vacuum glazed smart windows}

Vacuum glazed smart windows play an imperious role that determine heat gain or heat loss in net zero energy buildings. It is an assembly of vacuum glazing, sash, and frame as shown in Fig. 1. Vacuum glazing refers to the transparent part, with tiny little dots of support pillars, of a window [23]. The sash is a casing in which the glass sheets of a window are set, and the frame is the complete structural enclosure of the glazing [24]. Fenestration refers to the design and position of vacuum glazed smart windows in a NZEB. The thermal performance of the window depends on the number of glass sheets, the space between glass sheets, emissivity of the coatings on glass sheet, the frame in which the glass is installed, and the type of spacers that separate the sheets of glass. The use of window frame types has significant impact on the thermal transmittance values. Wood, vinyl or unplasticized polyvinyl chloride (UPVC) frames have greater heat resistance than metal [25], but some 
metal frame such as aluminium performance can be improved by introducing thermal isolation, or thermal break, between the cold side of the frame and the warm side by including low conducting materials.

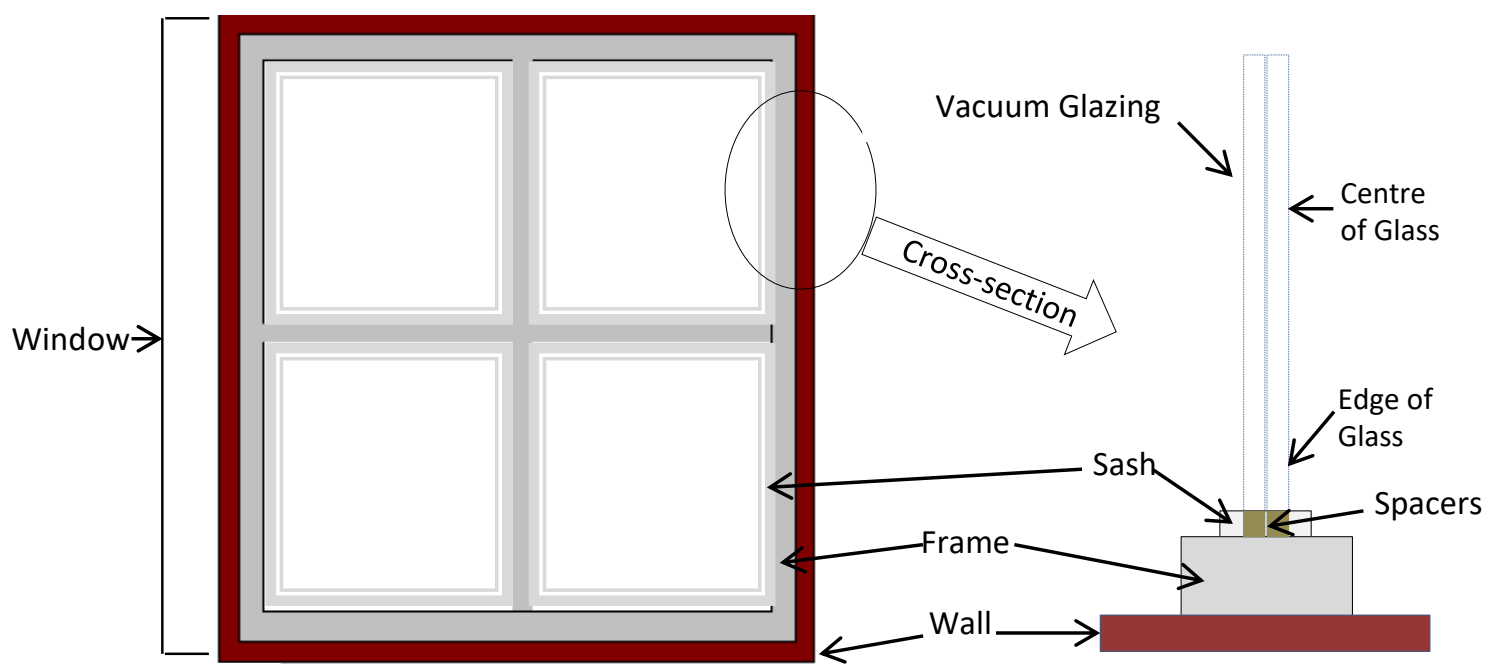

Not to scale

Fig. 1. Window components showing glazing layers separated with spacers and sits in the sash situated on the frame.

\subsection{Thermal transmittance - U value}

One of the main functions of a vacuum glazed smart window is to reduce heat flow between indoors and outdoors, i.e. to provide good thermal insulation [26]. The thermal conductance is the rate of total heat flow per unit area per degree of temperature difference between indoors and outdoors. The thermal transmittance is the addition of total thermal conductance with internal and external heat transfer coefficients. Both specified in units of $\mathrm{Wm}^{-2} \mathrm{~K}^{-1}(\mathrm{SI})$ or $\mathrm{BTUh}^{-1} \mathrm{ft}^{-2}$ (imperial). The relevant European standards, EN673 and EN674 [27], specify a temperature difference of $15 \mathrm{~K}$ between the external and internal glazing surface temperatures, whereas North American standards refer to the difference between the external and internal air temperatures. The $U_{\text {centre }}$ value according to EN673 [27] refers to the value at the centre of the glazing alone, without edge effects and the whole window, which is specified by $U_{w}$ (heat transfer coefficient of window), and includes the effect of the frame and the glazing edge area.

\subsection{Thermal resistance $-R$ value}

The thermal resistance, $R$ value, is a measurement of a temperature difference by which a glazing resists a heat flow in SI unit $\mathrm{m}^{2} \mathrm{KW}^{-1}$ (SI) or h. $\mathrm{ft}^{2} / \mathrm{BTU}$ (Imperial) [28]. It is the reciprocal of the thermal conductance. Thermal transmittance, $U$ value, is the reciprocal of the sum of external and internal surface thermal resistance and total thermal resistance of the glazing. Thermal resistance of homogeneous layer can be calculated by dividing thickness with thermal conductivity of material/layer. 


\subsection{Solar transmittance- $g$ value}

The solar heat gain is an increase in temperature in a space or material resulting due to solar radiation. The g value or Solar Heat Gain Coefficient (SHGC) is defined as the ratio of solar heat gain (W) through a unit area of glazing to the solar radiation (W) striking through a unit area of the outer surface, for a given incidence angle and given environmental conditions (indoor and outdoor temperature, wind speed) [29]. The total solar energy transmittance can be calculated by summing two components: the solar radiation which is transmitted by the glazing unit, and that portion of solar energy that is initially absorbed by the glazing and is then transferred as heat to the indoor environment. The $g$ value or solar factor ranges from 0 to 1 . The ideal $g$ value for a window is one that is high enough to allow solar radiation gains to heat a room effectively in winter months, reducing the need for conventional space heating, but low enough to avoid overheating in summer. Glazing with a g value lower than 0.5 [26] is often called solar control glazing, as it is intended for situations with abundant solar radiation that needs to be controlled to avoid overheating problems.

\subsection{Visible transmittance $-\tau_{v}$}

The visible light or light transmittance $\tau_{v}$ is defined as the ratio of light transmitted by the glazing to light incident on the glazing, for perpendicular incidence if not specified otherwise [26]. Generally, a higher value of $\tau_{v}$ is often desirable; that leads to more daylight indoors. However, in specific cases, low $\tau_{v}$ value may need to be chosen, e.g. if the contrast becomes too high to work with computer monitors. Values up to 0.81 can be obtained for high-performance glazing.

\subsection{Thermal resistance of a high vacuum pressure residual gas space}

The distance between the boundaries in which the gas is transporting heat, i.e. $0.15 \mathrm{~mm}$, is much lower than the mean free path, i.e. $1142 \mathrm{~m}$ as detailed in [30]. For this case, Collins et al. [31] have developed equation (i.e Eq. (1)) for the thermal conduction through the low-pressure residual air in the internal space which is valid when the vacuum pressure is less than or equal to $0.1 \mathrm{~Pa}$.

$C_{g a s} \approx 0.4 P$

According to Memon et al. [30], the experimental testing results have shown the achievable vacuum pressure in the vacuum system to be $4.35 \cdot 10^{-5} \mathrm{~Pa}$. Based on this the gaseous conduction in the space $\left(C_{\text {gas }}\right)$ is, from Eq. (1) calculated to be $1.74 \cdot 10^{-5} \mathrm{Wm}^{-2} \mathrm{~K}^{-1}$, which is considered a negligible value.

The heat transfer mainly occurs through radiation in the vacuum space and depends strongly on the surfaces and their emissivities (coated or uncoated) and the mean surface temperature $\left(T_{m}\right)$. In general, the emissivity of a surface depends on the angle of the radiation to the plane of the surface. The normal emissivity is the value of emissivity for radiation normal to the surface that is right angles to the plane surface. Hemispherical emissivity is the integration of the radiation over all angles that the surface is radiating $2 \pi$ steradians, radiative heat flow equations are detailed in [32]. For the uncoated glass surfaces the hemispherical emissivity is less than the normal emissivity, For the coated glass surfaces the hemispherical value is greater than the normal value, different surface emissivities are detailed in BS 6993 [33]. In Eq. (1) an effective emissivity of the surface was used due to the directionality of multiple reflections between two surfaces are taken into account, this can be 
determined if the emission properties of both surfaces with which surface is exchanging radiation are known.

The net radiation interchange between two surfaces is independent of the separation of the surfaces [31]. To obtain a conductance due to radiative heat transfer, the equation was linearised by a Taylor series expansion results in Eq. (2) which represents an approximation for the radiative conductance.

$C_{\text {rad }}=\frac{4 \sigma T_{m}^{3}}{\frac{1}{\varepsilon_{a}}+\frac{1}{\varepsilon_{b}}-1}$

where $\varepsilon_{a}$ and $\varepsilon_{b}$ are the effective emittance of the glass surfaces $a$ and $b$ facing each other across the vacuum space.

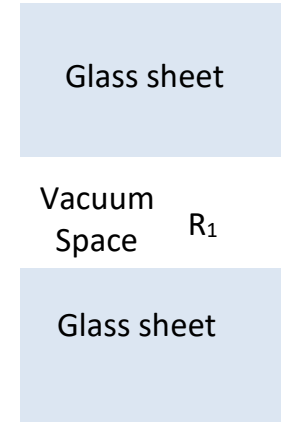

(a)

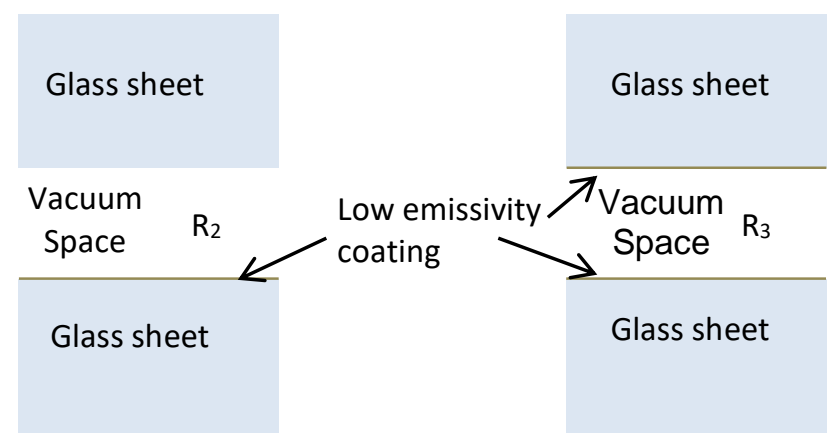

(b)

(c)

Fig. 2. The inner surface of two glass sheets bounding an enclosed vacuum space, (a) two surfaces are uncoated ( $\varepsilon$ of 0.845 each [33]), (b) one surface has a tin-oxide coating ( $\varepsilon$ of 0.15 ) and the other surface is uncoated ( $\varepsilon$ of 0.845 ), (c) both surfaces are coated with tin-oxide coating ( $\varepsilon$ of 0.15 each)

the effective conductance is calculated due to radiative heat transfer, between the inner surfaces of two glass sheets bounding the vacuum space, by choosing three different cases as shown in Fig. 2 . Fig. 2a shows two glass sheets with uncoated surfaces with an emissivity value of 0.845 (soda lime glass) and mean surface temperature $T_{m}$ of $283 \mathrm{~K}\left(10^{\circ} \mathrm{C}\right)$ based on [33]. From the Eq. (2), the value of $C_{\text {rad }}$ for this case is estimated to be $3.76 \mathrm{Wm}^{-2} \mathrm{~K}^{-1}$. Fig. $2 \mathrm{~b}$ plots two glass sheets in which one surface is tin-oxide coated, emissivity of 0.15 , and the other is uncoated. The value of $C_{\text {rad }}$ in this case is calculated to be $0.75 \mathrm{Wm}^{-2} \mathrm{~K}^{-1}$. Finally, Fig. $2 \mathrm{c}$ represents two glass sheets in which both surfaces are tin-oxide coated. The value of $C_{\text {rad }}$ in this case is calculated to be $0.42 \mathrm{Wm}^{-2} \mathrm{~K}^{-1}$.

The thermal resistance of the vacuum space is the reciprocal of the thermal conductance. The approximate thermal resistance of a vacuum space is the sum of the resistance through effective residual air in a high vacuum system and resistance due to long wave radiation and determined by Eq. (3).

$R=\frac{1}{C_{g a s}+C_{\text {rad }}}$

From Eq. (3), the thermal resistance of the vacuum space; case (a) two inner surfaces are uncoated is $0.27 \mathrm{~m}^{2} \mathrm{KW}^{-1}$, case (b), one inner surface is tin-oxide coated and the other is uncoated is $1.33 \mathrm{~m}^{2} \mathrm{KW}^{-1}$, case (c), both inner surfaces are tin-oxide coated is $2.38 \mathrm{~m}^{2} \mathrm{KW}^{-1}$. The details of the 
thermal transmittance when incorporating support pillars in double vacuum glazing and triple vacuum glazing are reported in [30,34].

\section{Factors influencing the performance parameters of vacuum glazed smart windows 4.1. Edge seal}

The hermetic edge seal of a vacuum glazing should be capable of maintaining a vacuum pressure of less than $0.1 \mathrm{~Pa}$, in order to suppress gaseous conduction, for the expected life span of 20 years required for a vacuum glazing [30]. Edge sealing of two glass sheets using a high-power laser through a quartz window in a vacuum chamber was developed by Benson et al [35]. Although this method achieved a hermetic seal, the level of vacuum was not less than the required, $0.1 \mathrm{~Pa}$, due to gases and vapour molecules caused by laser sealing technique [36]. A high temperature edge sealing technique was developed by the group at the University of Sydney, which is based on solder glass, as shown in Fig. $3 a$, that sealed at high temperatures around $450^{\circ} \mathrm{C}$ [37-39]. This technique was able to

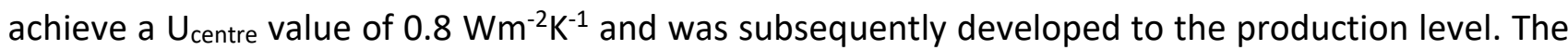
demerits of the high temperature edge sealing method are that it causes degradation of soft low emittance coatings meaning that only hard coatings can be used, and it uses lead-based solder glass. Toughened glass also cannot be used due to the loss of temper at high temperatures. Low temperature solder glass materials were investigated to form a hermetic edge seal, but durability was a problem due to the absorption of moisture. Polymers have problems of both gas permeability and out gassing [36].

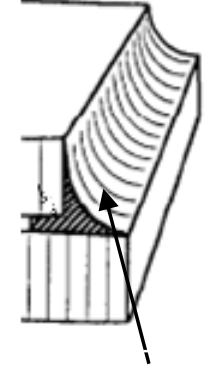

Solder glass

(a)

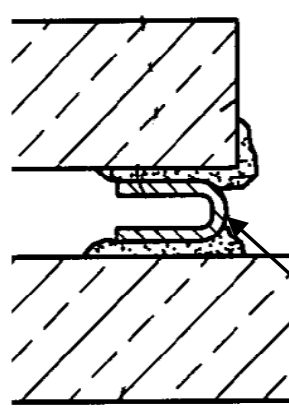

(b)
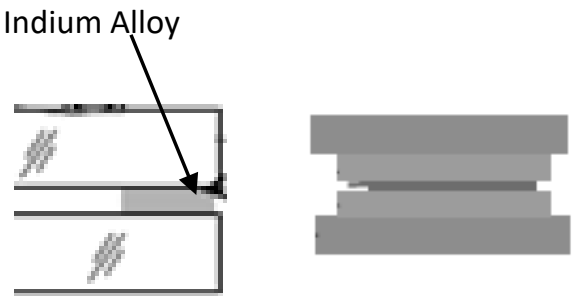

Cu-electrode (OV) Second glass pane Metal seal $(+1000 \mathrm{~V})$ Glass pane Cu-electrode (0V)

Soldered with Main edge seal CS-

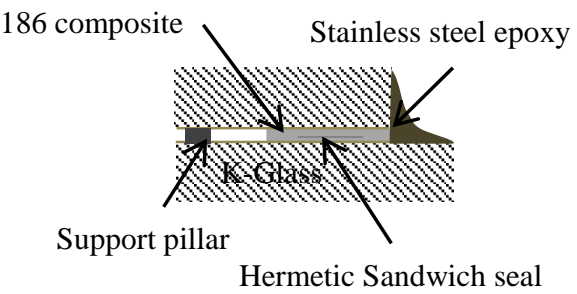

(e)

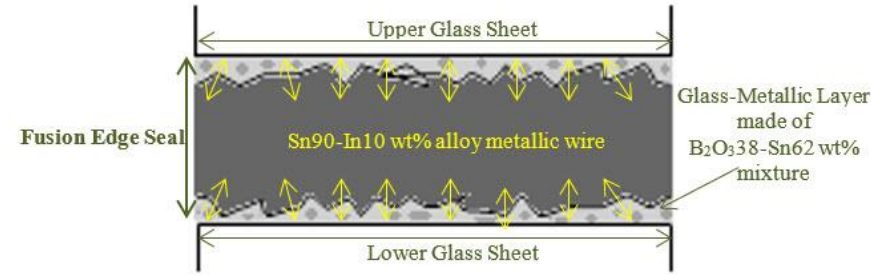

(f)

Fig. 3. Schematic diagram of edge seals to vacuum glazing made of (a) solder glass [38], (b) solder glass with metallic substrate [40], (c) indium alloy [41] (d) Dual interface anodic bonding of liquid metal seal [44], (e) CS$186\left(\mathrm{Sn}_{56} \mathrm{~Pb}_{39} \mathrm{Zn}_{3} \mathrm{Sb}_{1}\right.$ - AlTiSiCu $\mathrm{St}_{1} \mathrm{wt}$ ) composite with support of stainless steel epoxy [30] and (f) Fusion seal constructed with bonded $\mathrm{Sn} 62-\mathrm{B}_{2} \mathrm{O}_{3} 38$ wt\% mixture for surface texture fused with $\mathrm{Sn} 90-\ln 10 \mathrm{wt} \%$ alloy at high-temperature [46]

The use of a metallic gasket component and solder glass as an edge seal was patented by Cooper [40], as shown in Fig. 3b. The reason for using a metallic component was reported to be that when 
the edge seal is entirely made of solder glass, the direct contact could be disadvantageous in certain climate conditions such as in the hot, cold, or windy conditions and breakage of the window could also be possible under extremes of these conditions.

A low temperature edge sealing technique about $160^{\circ} \mathrm{C}$ developed at the University of Ulster based on indium or indium alloy, as shown in Fig. 3c. It requires secondary adhesive seal to protect the seal from moisture $[41,42]$. A low temperature sealing process allows the use of low emittance soft coatings which reduce radiative heat transfer between the glass sheets and also permits toughened glass to be used that allowing the increase in the supporting pillars spacing reducing conductive heat transfer in the pillar array. The main problem with the low temperature-based indium seal is the high cost; because of this the low temperature indium sealed vacuum glazing process has not yet been commercialised [36,43]. ALTSAB (Activated Liquid Tin Solder Anodic Bonding) is a dual interface anodic bonding (glass-metal-glass) technique [44]. This method uses SnAl0.6 wire, a tin solder alloy containing an activating aluminium metal which is anodically bonded to alkali rich glass substrates in the liquid state. This provides the ability to directly form glass-metalglass seals hermetically at a temperature $300^{\circ} \mathrm{C}$ using an electrochemical process, as illustrated in Fig. $3 \mathrm{~d}$. Due to the occurrence of oxidation at elevated temperatures in a solder metal surface, the edge sealing process has to be performed in a high vacuum environment $(0.005 \mathrm{~Pa})$. Dual interface bonding can produce sandwich structures, which can be useful for manufacturing glass-metal-glass objects or composites.

The recent successful construction of triple vacuum glazing, invented by Dr Memon, was based on ultrasonically soldering the primary seal, at low-temperature around $200^{\circ} \mathrm{C}$, made of composite CS-186 or Sn-Pb-Zn-Sb-AITiSiCu in the proportion ratio of 56:39:3:1:1 by wt\% and the secondary seal made of reinforced steel epoxy, as shown in Fig. 3e [30,45]. This composite hermetically sealed the edges of glass sheets and predicted the $\mathrm{U}$-value of $0.33 \mathrm{Wm}^{-2} \mathrm{~K}^{-1}$ and $0.91 \mathrm{Wm}^{-2} \mathrm{~K}^{-1}$ for triple vacuum glazing [34] and vacuum glazing [30], respectively. This method overcomes the high cost issue, without compromising the scope of using tempered glass and soft coatings, but its composite edge seal has higher percentage of lead $(\mathrm{Pb})$ and it is complex-to-construct, mainly due to the need of precision in ultrasonically soldering the edges of glass sheets. The fusion edge-seal is a cost-effective, energy efficient (ultrasonic soldering free), and Pd-free (hazardous substance free) solution [46]. The fusion edge-sealed vacuum glazing, constructed with bonded $\mathrm{Sn62}-\mathrm{B}_{2} \mathrm{O}_{3} 38$ wt\% surface textured fused with Sn90-In $10 \mathrm{wt} \%$ alloy at $450^{\circ} \mathrm{C}$, as shown in Fig $4 \mathrm{f}$. It can be achieved at the hot-plate surface heat induction of $50 \pm 5^{\circ} \mathrm{C}$ and the cavity vacuum pressure of $8.2 \cdot 10^{-4} \mathrm{~Pa}$. This technique can achieve a $\mathrm{U}_{\text {centre }}$ value of $1.039 \mathrm{Wm}^{-2} \mathrm{~K}^{-1}$ and is suitable for mass manufacturing level.

\subsection{Support pillar array}

An array of supporting pillars is required to maintain the narrow gap/vacuum space between the two glass sheets. The glass sheets are in contact with the pillars and endure from internal stresses and radial tensile stresses externally due to the difference between atmospheric and vacuum pressure [47]. The pillars should be made from an appropriate material, with size and spacing to withstand the external atmospheric pressure on the glazing [48]. Suitable pillar materials are divided into ceramics, such as alumina; and metals, such as stainless steel $\left(\mathrm{k}=16 \mathrm{Wm}^{-1} \mathrm{~K}^{-1}\right.$ and Inconel 718 (a nickel-based alloy, $\left.\mathrm{k}=11.4 \mathrm{Wm}^{-1} \mathrm{~K}^{-1}\right)$. Pillars are typically $0.125-0.25 \mathrm{~mm}$ in radius and $0.1-0.2 \mathrm{~mm}$ in height and they are generally positioned in a square array, separated by $20 \mathrm{~mm}-40 \mathrm{~mm}$ depending on the thickness of the glass sheet. The design of the pillars array is based on five design principles: 
(i) Compressive stress in the pillars should not exceed the allowable limit [49], (allowable compressive stress for stainless steel is assumed as 1.5GPa [43] or at least 1GPa [50].

(ii) The maximum external tensile stress in the glass sheet should not be exceeded; this limits the pillar separation in relation to the glass sheet thickness, the tolerable level of external tensile stress proposed is $4 \mathrm{MPa}$ due to atmospheric pressure on the outside surface of the glass sheets above the pillars $[49,51]$.

(iii) Indentation fracture should not appear in the glass near the support pillar.

(iv) The avoidance of any mechanical instability due to the tiny support pillar radii compared to their height.

(v) The supporting pillars should be hardly visible [43].

Figure 4 illustrates the selection of pillar radius in relation to pillar separation for two different thicknesses of glass sheets and a number of low emittance coatings, assuming the pillar thermal conductivity $\mathrm{k}_{\mathrm{p}}$ is $20 \mathrm{Wm}^{-1} \mathrm{~K}^{-1}$ and the emittance of the surfaces is 0.03 . The magnitude of the stresses above the pillars depends on the thickness of the glass sheet, increase of glass sheets thickness allows increase of pillar separation [41,52]. The shaded area represents appropriate design values of pillar separation and pillar radii. To make sure that the stresses do not exceed the required bending stress and deflection in the glass sheets, the pillars separation should be the maximum based on the glass thickness, glass type (tempered or untampered) and pillar radii [43]. Fig. 4a agrees with the Collin et al. [39] pillar radius and separation relation. With increasing the thickness of glass sheets, the pillar separation can be increased as shown in Fig. 4b.

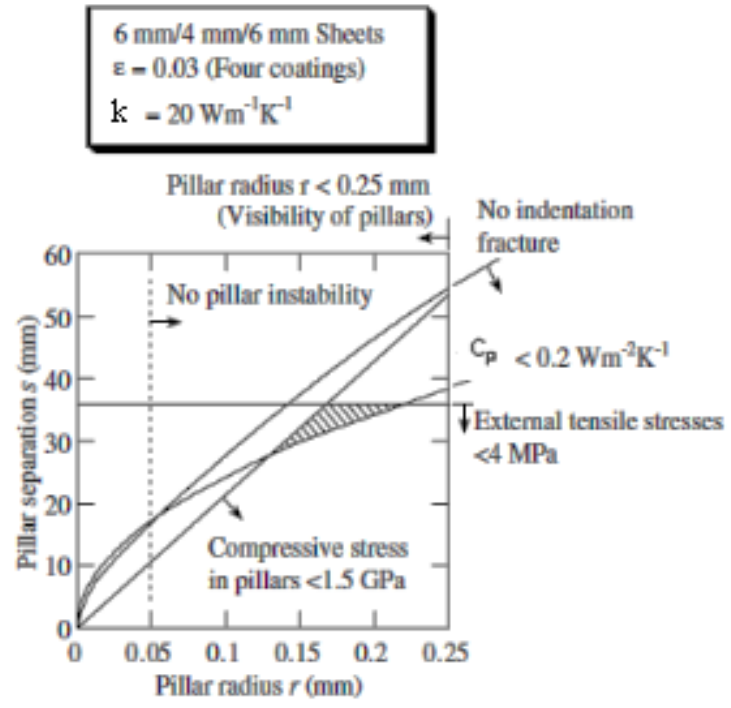

(a)

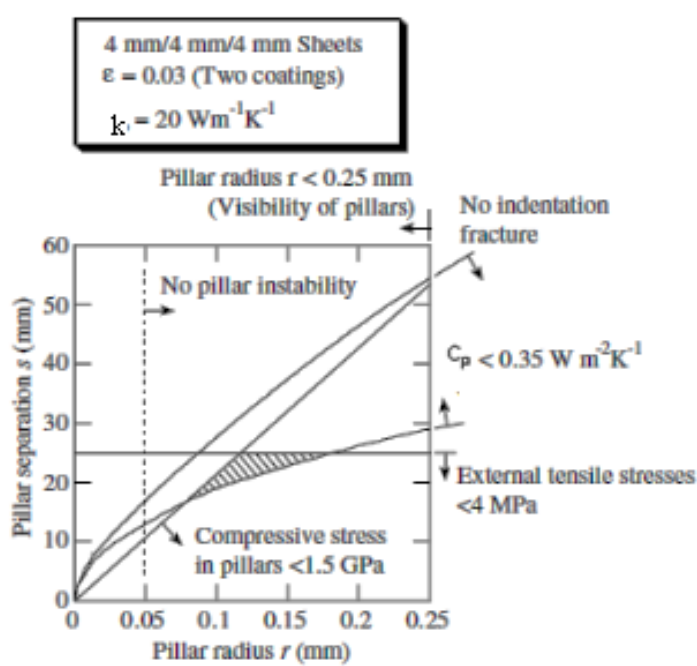

(b)

Fig. 4. (a) Design parameters for $4 \mathrm{~mm} / 4 \mathrm{~mm} / 4 \mathrm{~mm}$ triple vacuum glazing with two low-emittance coatings and thermal conductance of pillar array, $C_{p}<0.35 \mathrm{Wm}^{-2} \mathrm{~K}^{-1}$.(b) Design parameters for $6 \mathrm{~mm} / 4 \mathrm{~mm} / 6 \mathrm{~mm}$ triple vacuum glazing with four low-emittance coatings and thermal conductance of pillar array, $\mathrm{C}_{\mathrm{p}}<0.2 \mathrm{Wm}^{-2} \mathrm{~K}^{-1}$. The range of possible pillar radii and pillar separations is shaded [43]

Increasing pillar radii results in a higher rate of heat transfer through each pillar $\left(C_{p}\right)$, thus the $\mathrm{U}_{\text {centre }}$ value increases. Increasing the pillar separation leads to a decrease in the total thermal conductance, due to the reduction in the number of pillars required per unit area of the glass as shown in Fig. 5 [53]. 


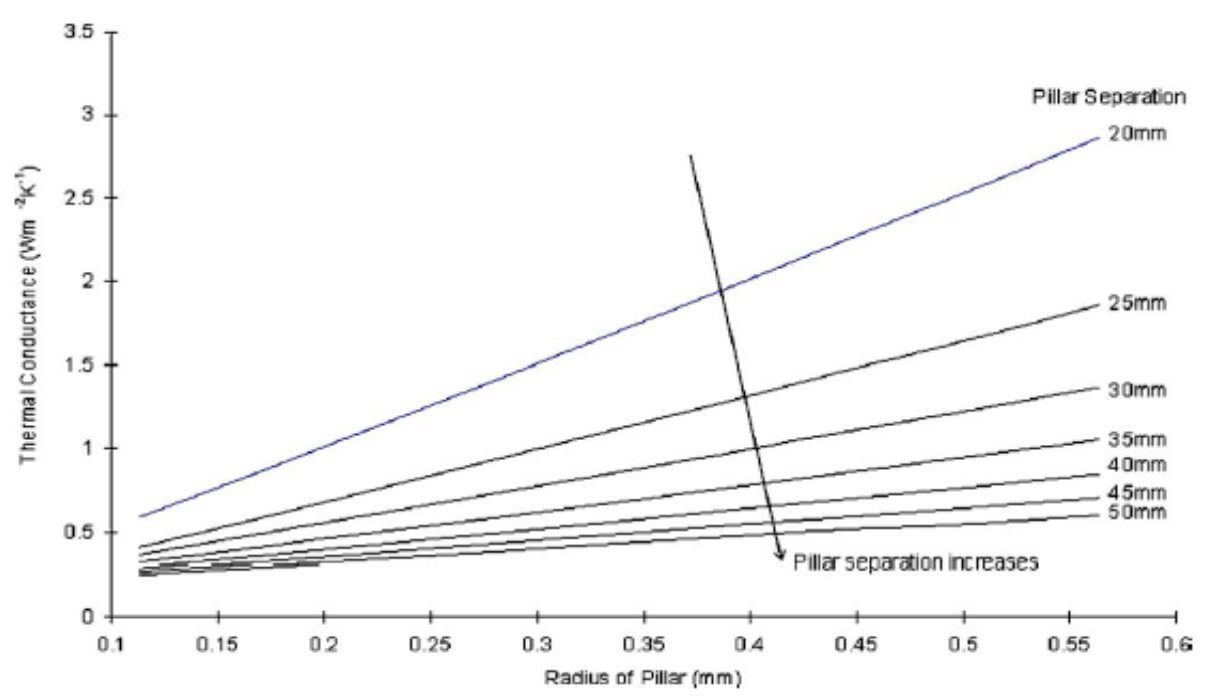

Fig. 5. Thermal performance of the centre of sheet $U$ value of a vacuum glazing with varying pillar radius and pillar separation [53].

\subsection{Low emittance coatings}

Emissivity $\varepsilon$ of a surface is a ratio of the radiation emitted by a surface to the radiation emitted by a blackbody at the same temperature [32], on a scale of 0 to 1 . Low emissivity refers to a surface that has low levels of radiant thermal energy emissions. A blackbody has an emissivity of 1 and a perfect reflector has an emissivity of 0 . Reflectivity is inversely proportional to emissivity and when summed for an opaque surface a value of 1 . For example, if the emittance of silver is 0.02 then its reflectance is 0.98 . This means it reflects more about $98 \%$ of the radiant energy and absorbs $2 \%$ of radiant energy. The emissivity depends on the temperature, emission angle, wavelength, and surface roughness. Soda lime glass has an emissivity of approximately 0.845 [33,54], pyrolytic coatings can achieve emissivities of approximately 0.40 , and sputter coating can produce emissivities of 0.10 and lower.

Low emittance coating can be applied on the surface of the glass sheet either by sputtering or pyrolytic coating processes. The lowest emissivities are achieved with a sputtering process by magnetically depositing (e.g. silver) to the glass inside a vacuum chamber [24]. Sputter coated surfaces must be protected within an insulated glass unit and are often called "soft coatings" and include coatings such as silver ( $\mathrm{Ag})$, Titanium dioxide $\left(\mathrm{TiO}_{2}\right)$, Zinc oxide $(\mathrm{ZnO})$, and Aluminium Oxide $\left(\mathrm{Al}_{2} \mathrm{O}_{3}\right)$ [41]. Pyrolytic coating is a method which applies tin oxide $\left(\mathrm{SnO}_{2}\right)$ to a glass surface while it is somewhat molten. The pyrolytic coatings have higher emissivities than sputter coatings; the surfaces are however more durable and can survive higher temperatures (up to $400^{\circ} \mathrm{C}$ before degrading).

The purpose of a low emittance coating on a glass sheet is to reduce heat loss due to long wave radiation. In triple vacuum glazing, decreasing the emittance of the coatings reduces the thermal transmittance, $U$ value. Fig. 6 . illustrates $U_{\text {centre }}$ and $U_{\text {total }}$ values for $0.5 \times 0.5 \mathrm{~m}$ and $1 \times 1 \mathrm{~m}$ triple vacuum glazings. The triple vacuum glazing $U_{\text {centre }}$ value is always less than the $U_{\text {total }}$ value because the latter includes conduction heat transfer due to the metallic edge seal of the glazing (e.g. indium alloy). The total conduction includes the support pillars. However, the simulated $U_{\text {total }}$ value of a $0.5 \times 0.5 \mathrm{~m}$ triple vacuum glazing with surface emittance of 0.03 is $0.84 \mathrm{Wm}^{-2} \mathrm{~K}^{-1}$, for a $1 \times 1 \mathrm{~m}$ glazing this is $0.64 \mathrm{Wm}^{-2} \mathrm{~K}$ ${ }^{1}$ [55]. This illustrates that increasing the size of the glazing decreases the impact of edge effects and 
therefore improves total thermal transmittance values; however, the $U_{\text {centre }}$ value is the same for both sizes as it doesn't include the edge effects and it is predicted to be $0.24 \mathrm{Wm}^{-2} \mathrm{~K}^{-1}$.

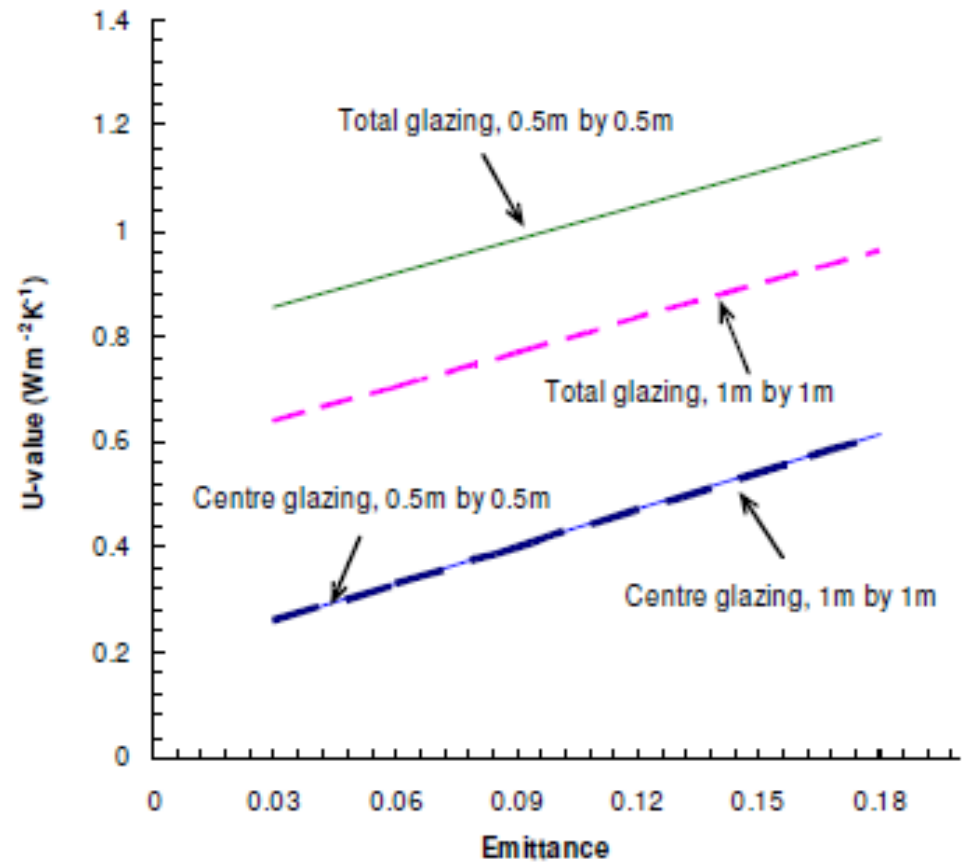

Fig. 6. $U$ value of the triple vacuum glazing with various emittances of low-e coatings [55]

The thermal performance not only depends on the size of the glazing but also on the number of low emittance coatings as shown in Fig. 7. The $U_{\text {centre }}$ and $U_{\text {total }}$ values of a triple vacuum glazing with one, two, three and four low emittance coatings of 0.18 are presented. Triple vacuum glazing with four low emittance coatings having simulated $U_{\text {centre }}$ value $16.63 \%$ and $U_{\text {total }}$ value $7.47 \%$ smaller than the glazing with three low emittance coatings. This shows that increasing the number of coatings on the glass surfaces decreases the heat transfer due to long wave radiation and improves the thermal performance. The simulation results indicated that when using three low-e coatings in a triple vacuum glazing, the vacuum gap with two low-e coatings should be set to the direction facing the hot side environment, while the vacuum gap with one coating should face the cold environment [55].

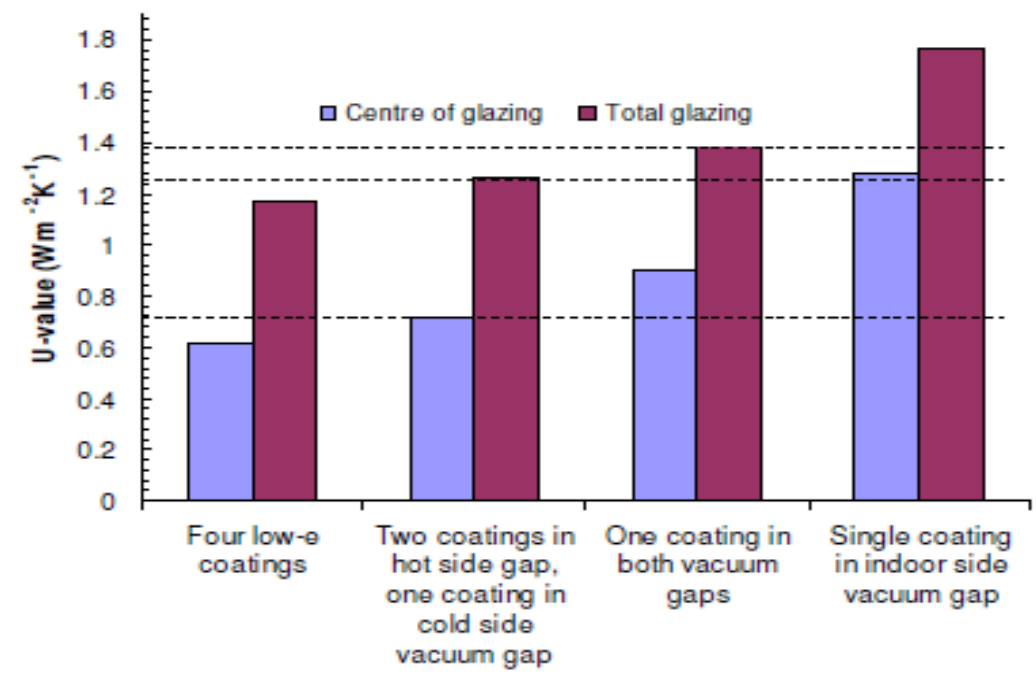

Fig. 7. Comparison of $U_{\text {centre }}$ and $U_{\text {total }}$ values of triple vacuum glazing with one, two, three, and four low-e coatings [55] 


\subsection{Getters}

Getters are reactive and highly porous materials that absorb any gases outgassed from the internal glass surfaces into the cavity of the vacuum glazing from the glass surface preventing degradation of system performance and providing long term vacuum stability of the glazing [56,57]. Outgassing occurs due to the release of a gas that was dissolved, trapped and/or absorbed either on the glass surface or on the edge sealing material. This leads to a conductive and convective heat transfer path through the cavity added to heat transfer through pillars and an edge seal. The spacers/pillars could also be used as a getter [58] but the design would be complex. Providing a getter separately is advantageous for pressure maintenance and removal of gas molecules. The assembly of a getter in a vacuum glazing unit is shown in Fig. 8, a getter material is enclosed between thxe two glass sheets, a 'bung' is sealed with frit such as solder glass or other sealing material.

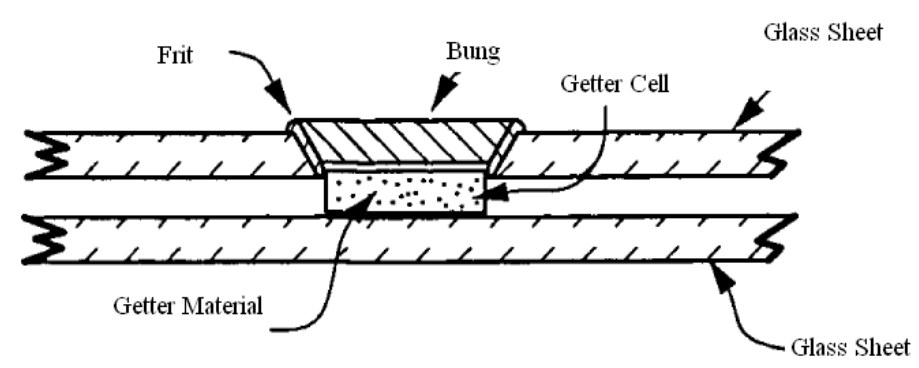

Fig. 8. Vacuum Glazing with Getter [58]

SAES Getters use materials formed of alloys or materials including barium, aluminium, magnesium, calcium, sodium, strontium, caesium, and or phosphorus [59]. SAES make sintered porous non evaporable getters (NEGs) that are available in planar form and with a total thickness of a few hundred microns and activation temperatures of $350-500^{\circ} \mathrm{C}$. Non-evaporable getters (NEGs) are generally made up of alloys of three materials from Zirconium, Titanium, Cobalt, Vanadium, Nickel, or Aluminium [59]. The use of vanadium is restricted due to its toxic nature. The disadvantage of NEG alloys is they raise exothermic reactions when the alloy is heated to $250^{\circ} \mathrm{C}$ that raises temperatures to around $1000^{\circ} \mathrm{C}$, endangering the safety of workers and degrading glass coatings. The NEG getter can be used for the low temperature sealed vacuum glazing by activating using induction heater. The activation temperature of NEG getter i.e. $350-500{ }^{\circ} \mathrm{C}$ would degrade low emittance coatings, if using an indium alloy as the edge seal with low-e silver coating on the glass surfaces.

A new gettering system, the Combogetter is pre-treated and sealed under argon in a blister package. Combogetters made of $\mathrm{CaO} / \mathrm{BaLi}_{4} / \mathrm{CO}_{3} \mathrm{O}_{4}$ in a layered structure do not require activation. $\mathrm{CaO}$ absorbs water and some $\mathrm{CO}_{2}, \mathrm{BaLi}_{4}$ absorbs nitrogen and a combination of $\mathrm{CO} / \mathrm{CO}_{2}, \mathrm{CO}_{3} \mathrm{O}_{4}$ absorbs $\mathrm{H}_{2}$. Due to its reactivity, exposure to air should be minimized to less than 5 minutes [59]. The Combogetter absorbs the out gassed and long-term permeating gases. Both NEG and Combogetter can be affected, in terms of their lifetime, depending on the number of gaseous molecules adsorbed on the internal surfaces of the vacuum cavity [60].

Using a Combogetter (thickness $6.5 \mathrm{~mm}$ and width $28 \mathrm{~mm}$ ) in a triple vacuum glazing is complex in the case of using three glass sheets of thickness $4 \mathrm{~mm}$ and vacuum gap of $0.13 \mathrm{~mm}$ [60]. It requires one complete circular hole in the middle glass sheet, $1.15 \mathrm{~mm}$ hole on other two glass sheets at the side of vacuum gap as shown in Fig. 9. Combogetter can be very difficult to be installed in a vacuum glazing due to the edge sealing, evacuation and pump-out sealing processes. 


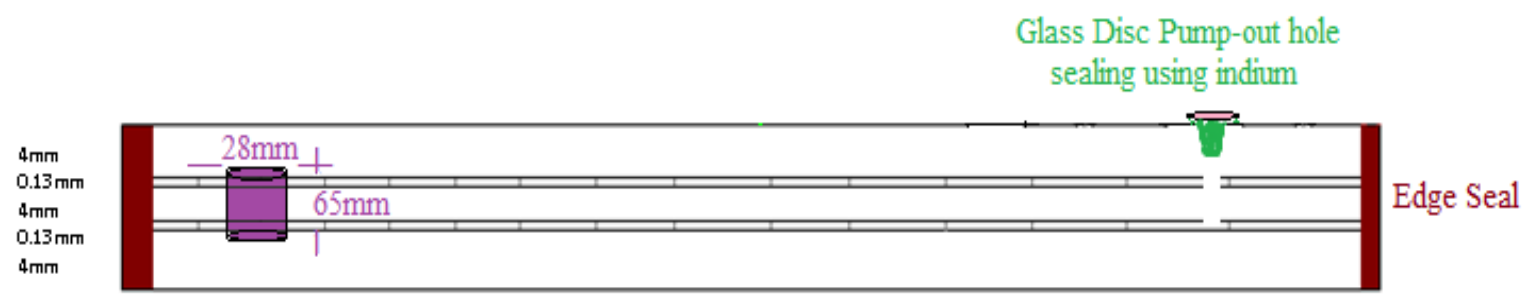

Fig. 9. Schematic diagram of Combogetter/NEG placement in a triple vacuum glazing [18]

\subsection{Evacuation}

The evacuation of the cavity/gap of vacuum glazing is done through its pump-out hole.It can be achieved with the high-vacuum pump-out system (consists of diaphragm pump and turbomolecular pump) that reduces the mass flow rate of gas pressure to less than $0.01 \mathrm{~Pa}$ [61]. It then needs to be sealed during evacuation. The gas flow through the vacuum pump-out system occurs due to the difference of pressure depending on the inside diameter of the tubes that determines the air flow conductance in litres/s [30]. However, the vacuum pressure within the cavity of vacuum glazing is typically measured during evacuation through Micro-Pirani pressure gauge that indicates an approximate pressure in the cavity but does not necessarily mean the post-fabrication vacuum pressure. The average distance of any air molecule, typically $4 \cdot 10^{-10} \mathrm{~m}$, travels before colliding with another molecule is its mean free path $\lambda$ in $m[62,63]$. When designing the high-vacuum pump-out system, it is suggested that the connections (tubes and pipe length) between the turbo-molecular pump and the vacuum cup need to be reduced so as to keep the pumping speed losses to a minimum level [30]. Under atmospheric pressure, $101.325 \mathrm{kPa}$, the mean free path between molecules is $56.35 \cdot 10^{-9} \mathrm{~m}$. As the air pressure decreases, the mean free path will increase. Ideally, the achievable vacuum pressure could be $5 \cdot 10^{-6} \mathrm{~Pa}$ then the mean free path between molecules can be $1142 \mathrm{~m}$ which is called a molecular flow regime. The rate of evacuation, i.e. gas flow rate, is proportional to the rate of mass of air change [64]. In addition to that, the layers of adsorbed gaseous molecules as a thin film on the internal surfaces within the tubes and vacuum glazing require longer evacuation, at least six hours, for achieving a good level of high vacuum pressure [65]. Increasing the temperature up to $60^{\circ} \mathrm{C}$ could help in desorbing the layers of gaseous molecules but this may cause glass bending. It may increase internal compressive and external tensile stresses in the glass sheets and an increase of a risk of cracking the edge seal $[66,67]$.

Figure 10 [30] shows the experimental measurements of the approximate cavity pressure under the hot plate surface temperature of $50^{\circ} \mathrm{C}$. As it can be seen, the vacuum pressure of approximately $0.042 \mathrm{~Pa}$ was achieved during the evacuation. The glass square was heated, using the heating element inside the vacuum cup, gradually to the melting temperature of this composite, i.e. $186^{\circ} \mathrm{C}$, during evacuation [30]. 


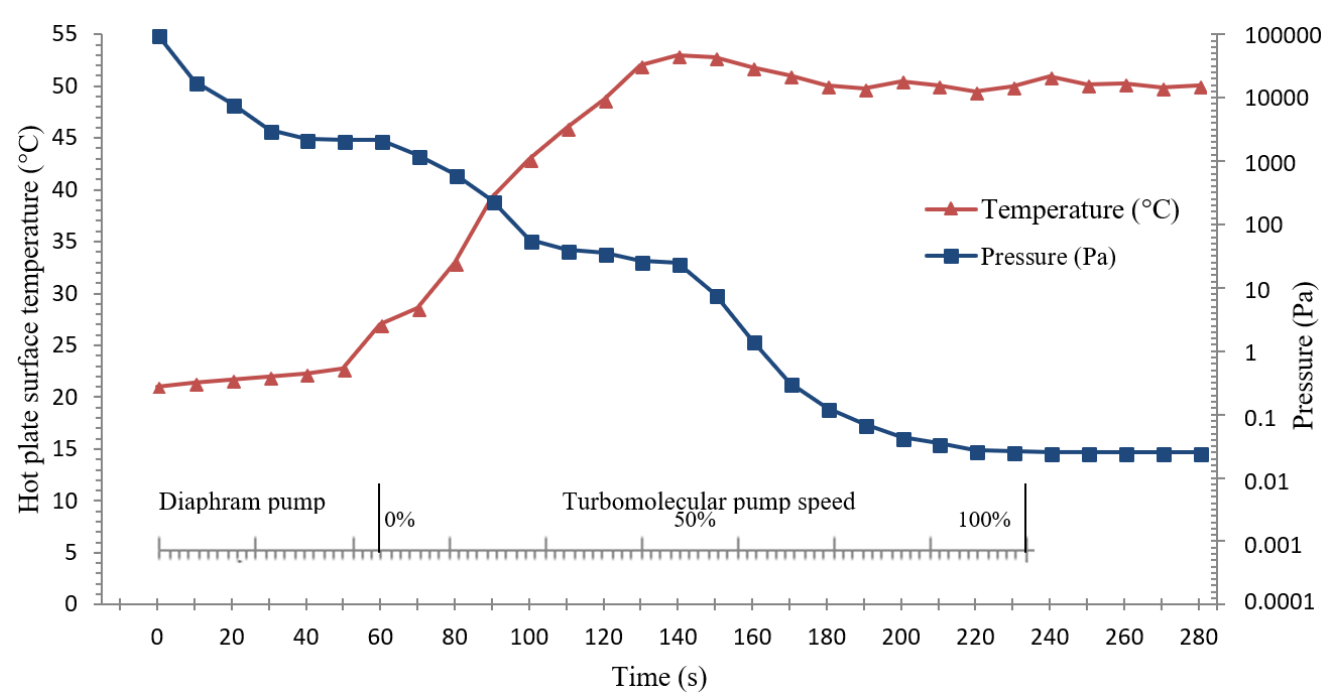

Fig. 10. Evacuation process for vacuum glazing showing vacuum pressure regimes at the hot-plate surface temperature induction at the set-point of $21^{\circ} \mathrm{C}$ in which it achieved $0.042 \mathrm{~Pa}$. [30].

\section{Conclusions}

This paper reviewed the parameters and influencing factors that determine the performance of vacuum glazed smart windows. This research work implicates that the performance parameters such as thermal transmittance, thermal resistance, solar transmittance, visible light transmittance and thermal resistance of residual gas space under high vacuum pressure are dependent on the factors, that require careful considerations, such as edge seal, support pillar array, low emittance coatings, getters and effective evacuation process. Although, an ideal vacuum glazed smart window may not exactly be possible. It is usually because of the trade-offs of achieving the balance between their achievable thermal transmittance, SHGC and thermal resistance of a high vacuum pressure residual gas space with respect to cost and stability of the vacuum pressure. However, inspirations of an ideal concept have inspired and challenged designers to evolve vacuum glazing to incorporate as many characteristics as possible, but the balance is importance. This research implicates that one of the most paramount factors that determine the performance of vacuum glazed smart window is its hermetic edge seal. Whilst recent advancements such as the use of fusion edge-sealed vacuum glazing seems to be cost-effective, energy efficient (ultrasonic soldering free), and Pd-free (hazardous substance free) solution. The width of the fusion edge seal could have compromised their $\mathrm{U}_{\text {centre }}$ value i.e. $1.039 \mathrm{Wm}^{-2} \mathrm{~K}^{-1}$. An acceptable use of stainless-steel type support pillar array seems to be an unavoidable compromise on the thermal transmittance value. It was shown that an increase of the size of glass sheet increases support pillar array and improving overall $U$ value. A factor of low emittance coatings plays a significant part in determining the performance of vacuum glazed smart windows and it was shown that overall $U$ value was improved with an increase of low emittance coatings whilst maintaining the visible light transmittance but it certainly increases the overall construction cost. To improve an overall life span of the vacuum glazed smart window, an incorporation of combo-getter that absorbs any gases out-gassed from the internal glass surfaces in to the vacuum cavity from the glass surface prevents degradation of vacuum pressure and provides long term vacuum pressure stability in the vacuum glazed smart window. A recent improvement in the understanding of evacuation process shows that hot-plate surface heat induction of $60^{\circ} \mathrm{C}$ can improve the vacuum pressure and also can mitigate the pump-out hole sealing process whilst lessening the temperature induced stresses. 


\section{Acknowledgement}

This work was supported by the Engineering and Physical Sciences Research Council (EPSRC) of the UK (EP/G000387/1) and Daiwa Anglo-Japanese Foundation Grant (12549/13360) (Project Leader: Dr Saim Memon and Project Partner: Dr Takao Katsura).

\section{Data Availability}

In support of open access research, all supplementary data to this article is available and can be found online at:

[dataset] Memon S. Design, fabrication and performance analysis of vacuum glazing units fabricated with low and high temperature hermetic glass edge sealing materials (Doctoral dissertation, Loughborough University). https://dspace.Iboro.ac.uk/2134/14562.

\section{References}

[1] Memon, S., T. Katsura, A. Radwan, S. Zhang, A. A. Serageldin, E. M. Abo-Zahhad, S. Sergey et al. "Modern eminence and concise critique of solar thermal energy and vacuum insulation technologies for sustainable low-carbon infrastructure." International Journal of Solar Thermal Vacuum Engineering 1, no. 1 (2020): 52-71. ISSN online (2716-6953).

https://doi.org/10.37934/stve.1.1.5271

[2] Butler, Declan. "Architects of a low-energy future: low-and zero-energy buildings could have a huge impact on energy use and carbon emissions. We have the technologies, but if they are to mitigate climate change, greenbuilding design must hit the mass market." Nature 452, no. 7187 (2008): 520-524. http://dx.doi.org/10.1038/452520a

[3] Liu, Zhongbing, Weijiao Li, Yazhen Chen, Yongqiang Luo, and Ling Zhang. "Review of energy conservation technologies for fresh air supply in zero energy buildings." Applied Thermal Engineering 148 (2019): 544-556. https://doi.org/10.1016/i.applthermaleng.2018.11.085

[4] Memon, Saim. "Analysing the potential of retrofitting ultra-low heat loss triple vacuum glazed windows to an existing UK solid wall dwelling." International Journal of Renewable Energy Development (IJRED) 3, no. 3 (2014): 161-174. https://doi.org/10.14710/ijred.3.3.161-174

[5] Uusitalo, Olavi, and Toni Mikkola. "Revisiting the case of float glass." European Journal of Innovation Management (2010). https://doi.org/10.1108/14601061011013212

[6] Pilkington, Lionel Alexander Bethune. "Review lecture: the float glass process." Proceedings of the Royal Society of London. A. Mathematical and Physical Sciences 314, no. 1516 (1969): 1-25. https://doi.org/10.1098/rspa.1969.0212

[7] Baetens, Ruben, Bjørn Petter Jelle, and Arild Gustavsen. "Properties, requirements and possibilities of smart windows for dynamic daylight and solar energy control in buildings: A state-of-the-art review." Solar energy materials and solar cells 94, no. 2 (2010): 87-105. https://doi.org/10.1016/i.solmat.2009.08.021

[8] Khan, Asif, Saim Memon, and Tariq Pervez Sattar. "Analyzing integrated renewable energy and smart-grid systems to improve voltage quality and harmonic distortion losses at electric-vehicle charging stations." IEEE Access 6 (2018): 26404-26415. https://doi.ord/10.1109/ACCESS.2018.2830187

[9] Memon, Saim. "Advanced Thermoelectric Materials for Energy Harvesting Applications." .IntechOpen Publisher, London, ISBN: 978-1-78984-529-7, (2020). https://doi.org/10.5772/intechopen.77430

[10] Memon, Saim, and Khawaja Noman, Tahir. "Experimental and analytical simulation analyses on the electrical performance of thermoelectric generator modules for direct and concentrated quartz-halogen heat harvesting." Energies 11, no. 12 (2018): 3315. https://doi.org/10.3390/en11123315

[11] Memon, Saim. "Introductory Chapter: Introduction to Advanced Thermoelectric Materials for Energy Harvesting Applications", Advanced Thermoelectric Materials for Energy Harvesting Applications, IntechOpen, London. (2019). https://doi.org/10.5772/intechopen.89640 
[12] Memon, Saim, Maekele Mihreteab, Takao Katsura, Ali Radwan, Shanwen Zhang, Ahmed A. Serageldin, and Essam M. Abo-Zahhad. "Experimental and theoretical performance evaluation of parabolic trough mirror as solar thermal concentrator to thermoelectric generators." International Journal of Solar Thermal Vacuum Engineering 1, no. 1 (2020): 22-38. ISSN online (2716-6953). https://doi.org/10.37934/stve.1.1.2238

[13] Makeen, Peter, Hani A. Ghali, and Saim Memon. "Experimental and Theoretical Analysis of the Fast Charging Polymer Lithium-Ion Battery Based on Cuckoo Optimization Algorithm (COA)." IEEE Access 8 (2020): 140486140496. https://doi.org/10.1109/ACCESS.2020.3012913

[14] Khan, Asif, Saim Memon, and T. P. Sattar. "Integration and management of solar energy for electric vehicle charging station." In Solar World Congress 2017-Innovation for the 100\% renewable energy transformation. Abu Dhabi, (2017). ISBN 978-3-981 465 9-7-6. https://doi.org/10.18086/swc.2017.16.03

[15] Ahmed, Mostafa, Ali Radwan, Ahmed Serageldin, Saim Memon, Takao Katsura, and Katsunori Nagano. "Thermal Analysis of a New Sliding Smart Window Integrated with Vacuum Insulation, Photovoltaic, and Phase Change Material." Sustainability 12, no. 19 (2020): 7846. https://doi.org/10.3390/su12197846

[16] Memon, Saim, and Philip C. Eames. "Predicting the solar energy and space-heating energy performance for solidwall detached house retrofitted with the composite edge-sealed triple vacuum glazing." Energy Procedia 122 (2017): 565-570. https://doi.org/10.1016/i.egypro.2017.07.419

[17] Aries, Myriam BC, Jennifer A. Veitch, and Guy R. Newsham. "Windows, view, and office characteristics predict physical and psychological discomfort." Journal of environmental psychology 30, no. 4 (2010): 533-541. https://doi.org/10.1016/i.jenvp.2009.12.004

[18] Memon, Saim. "Design, fabrication and performance analysis of vacuum glazing units fabricated with low and high temperature hermetic glass edge sealing materials." PhD diss., Loughborough University, 2013. https://dspace.lboro.ac.uk/2134/14562

[19] Gorgolis, Georgios, and Dimitris Karamanis. "Solar energy materials for glazing technologies." Solar Energy Materials and Solar Cells 144 (2016): 559-578.

https://doi.org/10.1016/i.solmat.2015.09.040

[20] Fang, Yueping, Saim Memon, Jingqing Peng, Mark Tyrer, and Tingzhen Ming. "Solar thermal performance of two innovative configurations of air-vacuum layered triple glazed windows." Renewable Energy 150 (2020): 167-175. https://doi.org/10.1016/i.renene.2019.12.115

[21] Hsiang, Solomon, Daniel Allen, Sébastien Annan-Phan, Kendon Bell, lan Bolliger, Trinetta Chong, Hannah Druckenmiller et al. "The effect of large-scale anti-contagion policies on the COVID-19 pandemic." Nature 584, no. 7820 (2020): 262-267. https://doi.org/10.1038/s41586-020-2404-8

[22] Rezaei, Soroosh Daqiqeh, Santiranjan Shannigrahi, and Seeram Ramakrishna. "A review of conventional, advanced, and smart glazing technologies and materials for improving indoor environment." Solar Energy Materials and Solar Cells 159 (2017): 26-51. https://doi.org/10.1016/i.solmat.2016.08.026

[23] Memon, Saim, and Philip C. Eames. "Solar energy gain and space-heating energy supply analyses for solid-wall dwelling retrofitted with the experimentally achievable U-value of novel triple vacuum glazing." Journal of Daylighting 4, no. 1 (2017): 15-25. https://doi.org/10.15627/id.2017.2

[24] Doty, Steve, and Wayne C. Turner. "Energy management handbook, 7th." (2009). http://dspace.uniten.edu.my/jspui/handle/123456789/14227

[25] Charlett, Andrew J., and Craig Maybery-Thomas. "Fundamental building technology". Routledge, (2013). ISBN13: 978-0-203-15517-2.

[26] Wilson, Helen Rose. "High-performance windows." Freidburg Solar Academy (2004).

[27] EN673, EN674 Glass in building. "Determination of thermal transmittance (U value) -Calculation method (EN673) and Guarded hot plate method (EN674) ", European National standards, (1997).

[28] Binggeli, Corky. "Building systems for interior designers". John Wiley \& Sons, (2003).

[29] Wright, John L., and Alex McGowan. "Calculating the solar heat gain of window frames." ASHRAE Transactions 105 (1999): 1011. 
[30] Memon, Saim, Yueping Fang, and Philip C. Eames. "The influence of low-temperature surface induction on evacuation, pump-out hole sealing and thermal performance of composite edge-sealed vacuum insulated glazing." Renewable energy 135 (2019): 450-464. https://doi.org/10.1016/i.renene.2018.12.025

[31] Collins, R. E., A. C. Fischer-Cripps, and J-Z. Tang. "Transparent evacuated insulation." Solar Energy 49, no. 5 (1992): 333-350. https://doi.org/10.1016/0038-092X(92)90106-K

[32] Bergman, Theodore L., Frank P. Incropera, David P. DeWitt, and Adrienne S. Lavine. "Fundamentals of heat and mass transfer". John Wiley \& Sons, (2011).

[33] BS 6993. "Thermal and radiometric properties of glazing-Part 1 Method for calculation of the steady state U-value (thermal transmittance) ". British Standards (1989).

[34] Memon, Saim, Farukh Farukh, Philip C. Eames, and Vadim V. Silberschmidt. "A new low-temperature hermetic composite edge seal for the fabrication of triple vacuum glazing." Vacuum 120 (2015): 73-82. https://doi.org/10.1016/j.vacuum.2015.06.024

[35] Benson, David K., C. Edwin Tracy, and Gary J. Jorgensen. "Laser sealed evacuated window glazings." In Optical Materials Technology for Energy Efficiency and Solar Energy Conversion III, vol. 502, pp. 146-151. International Society for Optics and Photonics, (1984).

[36] Eames, Philip C. "Vacuum glazing: Current performance and future prospects." Vacuum 82, no. 7 (2008): $717-722$. https://doi.org/10.1016/i.vacuum.2007.10.017

[37] Robinson, S. J., and R. E. Collins. "Evacuated windows-theory and practice." In ISES solar world congress, international solar energy society, Kobe, Japan. 1989.

[38] Collins, R. E., and S. J. Robinson. "Evacuated glazing." Solar Energy 47, no. 1 (1991): 27-38. https://doi.org/10.1016/0038-092X(91)90060-A

[39] Collins, Richard Edward, and Jian-Zheng Tang. "Design improvements to vacuum glazing." U.S. Patent 5,891,536, issued April 6, (1999).

[40] Cooper, David J. "Vacuum IG window unit with metal member in hermetic edge seal." U.S. Patent 7,919,157, issued April 5, (2011).

[41] Griffiths, P. W., Mariella di Leo, Peter Cartwright, P. C. Eames, P. Yianoulis, G. Leftheriotis, and Brian Norton. "Fabrication of evacuated glazing at low temperature." Solar Energy 63, no. 4 (1998): 243-249. https://doi.org/10.1016/S0038-092X(98)00019-X

[42] Zhao, J. F., Yueping Fang, Trevor Hyde, Jinlei Wang, and P. C. Eames. "Fabrication of low temperature sealed vacuum glazing using a modified pump-out technique." In Proceedings of CISBAT, pp. 201-206. 2005.

[43] Manz, H., S. Brunner, and L. Wullschleger. "Triple vacuum glazing: Heat transfer and basic mechanical design constraints." Solar Energy 80, no. 12 (2006): 1632-1642. https://doi.org/10.1016/i.solener.2005.11.003

[44] Koebel, Matthias M., Heinrich Manz, Karl Emanuel Mayerhofer, and Beat Keller. "Service-life limitations in vacuum glazing: A transient pressure balance model." Solar energy materials and solar cells 94, no. 6 (2010): 1015-1024. https://doi.org/10.1016/i.solmat.2010.02.003

[45] Memon, Saim. "Experimental measurement of hermetic edge seal's thermal conductivity for the thermal transmittance prediction of triple vacuum glazing." Case studies in thermal engineering 10 (2017): 169-178. https://doi.org/10.1016/i.csite.2017.06.002

[46] Memon, Saim, and Philip C. Eames. "Design and development of lead-free glass-metallic vacuum materials for the construction and thermal performance of smart fusion edge-sealed vacuum glazing." Energy and Buildings (2020): 110430. https://doi.org/10.1016/i.enbuild.2020.110430

[47] Memon, Saim. "Thermal Conductivity Measurement of Vacuum Tight Dual-Edge Seal for the Thermal Performance Analysis of Triple Vacuum Glazing." Impact of Thermal Conductivity on Energy Technologies (2018): 133. http://dx.doi.org/10.5772/intechopen.74255

[48] Zhang, Shanwen, Min Kong, Hong Miao, Saim Memon, Yanjun Zhang, and Sixing Liu. "Transient temperature and stress fields on bonding small glass pieces to solder glass by laser welding: Numerical modelling and experimental validation." Solar Energy 209 (2020): 350-362. https://doi.org/10.1016/i.solener.2020.09.014

[49] Fischer-Cripps, Anthony Craig, R. E. Collins, G. M. Turner, and E. Bezzel. "Stresses and fracture probability in evacuated glazing." Building and environment 30, no. 1 (1995): 41-59. https://doi.org/10.1016/0360-1323(94)E0032-M

[50] Wilson, C. F., T. M. Simko, and R. E. Collins. "Heat conduction through the support pillars in vacuum glazing." Solar Energy 63, no. 6 (1998): 393-406. 
https://doi.org/10.1016/S0038-092X(98)00079-6

[51] Collins, R. E., and T. M. Simko. "Current status of the science and technology of vacuum glazing." Solar Energy 62, no. 3 (1998): 189-213. https://doi.org/10.1016/S0038-092X(98)00007-3

[52] Zhang, Shanwen, Min Kong, Saim Memon, Hong Miao, Yanjun Zhang, and Sixing Liu. "Thermal Analysis of a New Neutron Shielding Vacuum Multiple Glass." Sustainability 12, no. 8 (2020): 3083. https://doi.org/10.3390/su12083083

[53] Griffiths, Philip W., Philip C. Eames, Trevor J. Hyde, Yueping Fang, and Brian Norton. "Experimental characterization and detailed performance prediction of a vacuum glazing system fabricated with a low temperature metal edge seal, using a validated computer model." (2006): 199-203.

https://doi.org/10.1115/1.2188529

[54] Memon, Saim. "Design, development and thermal performance analysis of ultra-low heat loss triple vacuum glazing." In Solar World Congress 2017-Innovation for the 100\% renewable energy transformation. Abu Dhabi. (2017) ISBN 978-3-981 465 9-7-6. https://doi.org/10.18086/swc.2017.15.04

[55] Fang, Yueping, Trevor Hyde, and Neil Hewitt. "The influence of emittance of low-emittance coating on the thermal performance of triple vacuum glazing." In The second IASTED International conference on solar energy, pp. 921928. International Association of Science and Technology for Development, (2010).

[56] Zhao, Jun Fu, Philip C. Eames, Trevor J. Hyde, Yueping Fang, and Jinlei Wang. "A modified pump-out technique used for fabrication of low temperature metal sealed vacuum glazing." Solar Energy 81, no. 9 (2007): 1072-1077. https://doi.org/10.1016/i.solener.2007.03.006

[57] Zhao, Jun Fu, Philip C. Eames, Trevor J. Hyde, Yueping Fang, and Jinlei Wang. "A modified pump-out technique used for fabrication of low temperature metal sealed vacuum glazing." Solar Energy 81, no. 9 (2007): 1072-1077. https://doi.org/10.1016/i.solener.2007.03.006

[58] Aggas, Steven L., and Vijayen S. Veerasamy. "Vacuum IG unit with spacer/pillar getter." U.S. Patent 6,420,002, issued July 16, (2002).

[59] SAES getter. "Technical specification SG-COMBO3/28-7/30510", SAES advanced technology S.P.A, Italy, (2007).

[60] Manini, Paolo. The Combogetter as a key component in the vacuum insulated panels (VIPs) technology, SAES Getters S.P.A, Italy, (1997).

[61] Memon, Saim, and Philip C. Eames. "Heat load and solar gain prediction for solid wall dwellings retrofitted with triple vacuum glazing for selected window to wall area ratios." In World Renewable Energy Forum, WREF 2012, vol. 6, pp. 4636-4643. ASES, 2012. ISBN: 9781622760923

[62] Guthrie, A. "Vacuum Technology". John Wiley and Sons, Inc, New York, (1963).

[63] Corruccini, R. J. "Gaseous heat conduction at low pressures and temperatures." Vacuum 7 (1959): 19-29. https://doi.org/10.1016/0042-207X(59)90766-3

[64] Miao, Hong, Lingcong Zhang, Sixing Liu, Shanwen Zhang, Saim Memon, and Bi Zhu. "Laser Sealing for Vacuum Plate Glass with PbO-TiO2-SiO2-RxOy Solder." Sustainability 12, no. 8 (2020): 3118. https://doi.org/10.3390/su12083118

[65] Memon, Saim. "Investigating energy saving performance interdependencies with retrofit triple vacuum glazing for use in UK dwelling with solid walls, Sustainable Development on Building and Environment." In Sustainable Development on Building and Environment: Proceedings of the 7th International Conference, 2015. ISBN-13: 9780993120701.

[66] Katsura, Takao, Saim Memon, Ali Radwan, Makoto Nakamura, and Katsunori Nagano. "Thermal performance analysis of a new structured-core translucent vacuum insulation panel in comparison to vacuum glazing: Experimental and theoretically validated analyses." Solar Energy 199 (2020): 326-346. https://doi.org/10.1016/j.solener.2020.02.030

[67] Radwan, Ali, Takao Katsura, Saim Memon, Ahmed A. Serageldin, Makoto Nakamura, and Katsunori Nagano. "Thermal and electrical performances of semi-transparent photovoltaic glazing integrated with translucent vacuum insulation panel and vacuum glazing." Energy Conversion and Management 215 (2020): 112920. https://doi.org/10.1016/i.enconman.2020.112920 